\title{
RELEASE KINETICS AND ANTIOXIDANT ACTIVITY OF B-CAROTENE ENCAPSULATED IN STARCH-CHITOSAN/TRIPOLYPHOSPHATE MATRICES
}

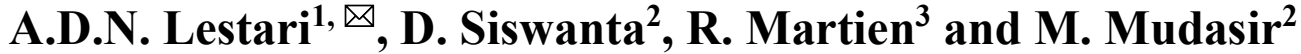 \\ ${ }^{1}$ Department of Chemistry, Faculty of Mathematics and Natural Sciences, Universitas Papua, \\ Manokwari-98314, Papua Barat, Indonesia \\ ${ }^{2}$ Department of Chemistry, Faculty of Mathematics and Natural Sciences, Universitas Gadjah \\ Mada, Yogyakarta-55281, DIY, Indonesia \\ ${ }^{3}$ Department of Pharmaceutics, Faculty of Pharmacy, Universitas Gadjah Mada, Yogyakarta- \\ 55281, DIY, Indonesia \\ ${ }^{\otimes}$ Corresponding Author: a.dyahnovitasari@gmail.com
}

\begin{abstract}
The efficacy of the drug encapsulated in the polymeric matrix is closely related to the kinetics of drug release from the matrix, therefore the study about the kinetic release of a drug from a certain matrix is essential to be carried out. This study aims to evaluate the release of $\beta$-carotene from the starch-chitosan crosslinked by tripolyphosphate matrices (starch-chitosan/TPP) in the in vitro digestive media (artificial intestinal fluid (AIF) and artificial gastric fluid (AGF)) as well as in ethanol, and to evaluate the antioxidant activity of the released $\beta$-carotene. The effect of starch types, i.e. native and acid hydrolyzed starch, on both parameters was investigated. The results show that the $\beta$-carotene release in AIF is slower than that in AGF. In each applied medium, the release rate of $\beta$-carotene from hydrolyzed starchchitosan/TPP matrices is slower than from native starch-chitosan/TPP matrices. The release kinetics of $\beta$-carotene in absolute ethanol medium follows the Korsmeyer-Peppas model with an exponent of release (n) value for encapsulation products using the native starch-chitosan/TPP matrix and using the hydrolyzed starch-chitosan/TPP matrix are 0.14 and 0.16 , respectively. This value indicates that the mechanism of $\beta$-carotene release in both matrices follows the quasi-fickian diffusion. Furthermore, the antioxidant activity of $\beta$-carotene released from the matrices does not decrease significantly after encapsulation, indicating the effectiveness of the matrices in protecting the activity $\beta$ carotene.
\end{abstract}

Keywords: Starch, Chitosan, TPP, $\beta$-carotene, Release Kinetics, Antioxidant Activity.

RASĀYAN J. Chem., Vol. 14, No.3, 2021

\section{INTRODUCTION}

The study of the application of natural polymers in drug delivery systems is an interesting topic for researchers today. ${ }^{1-3}$ Starch, a natural polymer, has been used as a matrix in the encapsulation of $\beta$ carotene. ${ }^{4}$ Starch can be combined with other natural polymers such as chitosan-crosslinked TPP to enhance its performance as an encapsulation matrix. ${ }^{5-7}$ One of the important studies about the encapsulated drug is the kinetic release of the drug from the matrix. This study is crucial to determine the stability of the drug in the body and to better understand its therapeutic effect so that it will allow us to determine the suitable formulation and control the release. ${ }^{8,9}$ The control of drug release reduces the frequency of taking medication and reduces local or systemic side effects. ${ }^{10}$ It has been reported recently that the release test of an anticancer drug bis-dimethoxy curcumin analog (BDMCA) from nanocomposite matrix of starchchitosan/TPP shows a very slow and continuous controlled diffusion release which provides increased bioavailability. ${ }^{6}$ In another study, the use of matrix starch-chitosan mixtures with TPP as crosslinkers for salicylic acid delivery from the fibers through the spinning method also shows an effective controlled release of the salicylic acid. In the encapsulated drug, it has been well known that the composition ratio of the matrix components influenced the rate of release. The greater the drug content in the matrix, the slower the release rate. ${ }^{5}$

Rasayan J. Chem., 14(3), 1729-1735(2021)

http://doi.org/10.31788/RJC.2021.1436217

This work is licensed under a CC BY 4.0 license. 
Previously, we have successfully synthesized $\beta$-carotene microparticles in a starch-chitosan/TPP matrix using a modified micro-precipitation method. ${ }^{7,11}$ Characterization of the product using FTIR and particle size analyzer as well as morphological characterization (SEM and TEM) and XRD have also been reported. ${ }^{7,11}$ However, the kinetic release and antioxidant activity performance of encapsulated $\beta$-carotene have not been systematically investigated in detail yet. Therefore, in this study, we report the results of a detailed study about the release kinetics of $\beta$-carotene encapsulated in the starch-chitosan/TPP matrix and the antioxidant activity test of the released $\beta$-carotene.

\section{Materials}

\section{EXPERIMENTAL}

The chemicals used in this study consist of starch from corn, chitosan, TPP, and $\beta$-carotene from Sigma Aldrich; ethanol and glacial acetic acid from Merck and demineralized water.

\section{Instruments}

The following instruments were particularly used to carry out the study and to characterize the products, namely a centrifuge (Sorfall Biofuge Primo), freeze-dryer (Leybold-Heraeus Lyovac GT 2), UV-Vis spectrophotometer (Shimadzu UV-1800), and multimode Microplate Reader (SPARK TECAN).

\section{Synthesis of Hydrolyzed Starch}

Hydrolysis of starch was carried out according to previously reported literature. ${ }^{12}$ Native starch $(100 \mathrm{~g})$ was added to $500 \mathrm{~mL} 0.15 \mathrm{M} \mathrm{HCl}$ in a three-neck flask. The mixture was heated at $50{ }^{\circ} \mathrm{C}$ while stirring for 8 hours. The solution was then filtered, washed with distilled water and dried for 48 hours at $30^{\circ} \mathrm{C}$.

\section{Synthesis of Microcapsules}

Microcapsule synthesis was carried out according to reported procedures ${ }^{4,11}$ using two types of starch, i.e. native starch and hydrolyzed starch. The encapsulation products were denoted as FN for encapsulation using native starch, and FH for encapsulation using hydrolyzed starch. Dispersion of starch was done by boiling $1 \%$ starch mixture in water. Solution of $1 \%$ chitosan was prepared in $1 \%$ acetic acid solution. TPP solution of 3\% was prepared in water. After all matrix materials were ready, then $20 \mathrm{~mL}$ TPP solution was added into $100 \mathrm{~mL}$ starch dispersion, and it was stirred. To the starch-TPP mixture, chitosan solution (100 $\mathrm{mL}$ ) was then added, stirred with a magnetic stirrer and heated for $10 \mathrm{~min}$ at $90{ }^{\circ} \mathrm{C}$. A volume of $100 \mathrm{~mL}$ of $\beta$-carotene dispersed in ethanol $(5 \mathrm{mg} / 100 \mathrm{~mL})$ was then added to the matrix mixture dropwise. The mixture was allowed to cool to ambient temperature and again the dropwise of $100 \mathrm{~mL}$ of $\beta$-carotene dispersion in ethanol $(5 \mathrm{mg} / 100 \mathrm{~mL})$ was added. The mixture was stored for one night, centrifuged at 7000 $\mathrm{x} \mathrm{g}$ for $10 \mathrm{~min}$, washed with $100 \mathrm{~mL}$ of ethanol, dried in a freeze-dryer for 13 hours and finally crushed, and sieved. Complete characterization of the products has been reported previously.,11

\section{Determination of $\beta$-carotene Content}

The amount of encapsulated $\beta$-carotene was determined according to the literature procedures with a few modifications. ${ }^{13,14}$ Microcapsule sample of $5 \mathrm{mg}$ was added with $1 \mathrm{~mL} \mathrm{HCl} 2 \mathrm{M}$ and heated at $75^{\circ} \mathrm{C}$ for 3 minutes in a water bath. After cooling, $2 \mathrm{~mL}$ of ethanol and $3 \mathrm{~mL}$ of hexane in a test tube were added to the dispersion and then subjected to vortex until the powder was bleached. The supernatant was taken and its absorbance was measured with a UV-Vis spectrophotometer at $450 \mathrm{~nm}$. The concentration of $\beta$-carotene was calculated by standard curve method constructed using the same manner as the sample.

\section{$\beta$-Carotene Release Test}

In vitro $\beta$-carotene Release Test in Digestive Media (artificial gastric and intestinal fluid/AGF and AIF)

AGF $(\mathrm{pH}=1)$ without enzymes addition was prepared by dissolving $200 \mathrm{mg} \mathrm{NaCl}$ and $0.7 \mathrm{~mL} 37 \%$ of $\mathrm{HCl}$ in distilled water up to $100 \mathrm{~mL}$. AIF medium ( $\mathrm{pH}$ 6.8) without enzymes consists of a $500 \mathrm{~mL}$ aqueous solution containing $0.1523 \mathrm{~g} \mathrm{MgCl}_{2}, 0.1470 \mathrm{~g} \mathrm{CaCl}_{2}, 0.0931 \mathrm{~g} \mathrm{KCl}, 1.7585 \mathrm{~g} \mathrm{NaCl}$ and $0.4200 \mathrm{~g} \mathrm{NaHCO}_{3}$. 
A total of $100 \mathrm{mg}$ of encapsulation product samples were inserted in $10 \mathrm{~mL}$ of the release media in an Erlenmeyer. A volume of $0.4 \mathrm{~mL}$ sample was taken at certain intervals $(1,2,3,4,24,48$, and 72 minutes). Every time a sample was taken, an additional $0.4 \mathrm{~mL}$ of media solution was added to the Erlenmeyer to compensate for the reduced volume. The captured snippet is then filtered. The filtrate was extracted with a solvent mixture of $0.6 \mathrm{~mL}$-hexane; $0.4 \mathrm{~mL}$ ethanol and 2 drops of $\mathrm{HCl} 2 \mathrm{M}$. The absorbance of hexane fraction was monitored by a Multimode Microplate Reader at a wavelength of $450 \mathrm{~nm}$, and the concentration of $\beta$-carotene was calculated by a standard curve prepared in the same manner as the sample. The released $\beta$-carotene (\%) is defined as the weight ratio (in percent) of the $\beta$-carotene released $\left(C_{\beta C}^{\prime} \times V\right)$ to the initial $\beta$-carotene in the sample $\left(L C x m_{e p}\right)$. The $\beta$-carotene release (\%) is determined by Eqn.-(1).

$$
\% \text { Release }=\left(C_{\beta C}^{\prime} \times V\right) /\left(L C \times m_{e p}\right) \times 100 \%
$$

Where:

$\mathrm{C}_{\beta C}^{\prime}=$ measured $\beta$-carotene concentration $(\mathrm{mg} / \mathrm{L})$

$\mathrm{V}=$ total volume of solution $(\mathrm{L})$

$\mathrm{LC} \quad=$ loading capacity $(\mathrm{mg} / \mathrm{g})$

$m_{e p} \quad=$ weight of encapsulation product sample $(\mathrm{g})$

The kinetic models of the release were evaluated from the $\%$ release data obtained at various times ( $\mathrm{t}$ ) based on kinetic equation models listed in Table-1, e.g. zero-order, first-order, Higuchi, and Korsmeyer-Peppas (KP) kinetic models.

Table-1:Kinetic Equation Models used in the Release Study

\begin{tabular}{l|l|l|l}
\hline No. & Kinetic Models & Equations & Types of Linear Plot \\
\hline 1 & Zero-order & {$[\mathrm{A}]_{\mathrm{t}}=[\mathrm{A}]_{0}-\mathrm{kt}$} & time $(\mathrm{t})$ vs \% release \\
\hline 2 & First order & $\ln [\mathrm{A}]_{\mathrm{t}}=-\mathrm{kt}+\ln [\mathrm{A}]_{0}$ & time $(\mathrm{t})$ vs $\log (\%$ retain $)$ \\
\hline 3 & Higuchi & $\mathrm{Q}=\mathrm{k} \sqrt{\mathrm{t}}$ & the square root of time $(\sqrt{\mathrm{t}})$ vs \% release \\
\hline 4 & Korsmeyer Peppas & $\mathrm{M}_{\mathrm{t}} / \mathrm{M}_{\infty}=\mathrm{kt}^{\mathrm{n}}$ & log time $(\mathrm{t})$ vs log $(\%$ release $)$ \\
\hline
\end{tabular}

$(\mathrm{t}), \mathrm{Q}=$ percentage of drug release at certain $\mathrm{t}, \mathrm{M}_{\mathrm{t}} / \mathrm{M}_{\infty}=$ Cumulative fraction of drug release at certain $\mathrm{t}$.

\section{$\beta$-Carotene Release Test on Absolute Ethanol Media}

The $\beta$-carotene release test in absolute ethanol medium was carried out by weighing $100 \mathrm{mg}$ of powder sample and dispersing it in $50 \mathrm{~mL}$ ethanol in a closed Erlenmeyer which was placed in a rotary shaker incubator maintained at $37^{\circ} \mathrm{C}$ and operated at a speed of $120 \mathrm{rpm}$. The 4-mL samples were taken every 5, $10,15,20,30,45,60,120,180,240,300$, and 360 minutes intervals. Each taken sample was replaced by the addition of $4 \mathrm{~mL}$ of ethanol to the system. Samples were filtered and the absorbance of $\beta$-carotene was recorded on a UV-Vis spectrophotometer at $450 \mathrm{~nm}$ of wavelength. The $\beta$-carotene concentration was determined by a standard curve and the percentage of released $\beta$-carotene (\% Release) is calculated according to Eqn.-(1).

\section{B-Carotene encapsulated Antioxidant Activity Test}

The test of antioxidant activity was conducted using the DPPH (2,2-Diphenyl-1-picrylhydrazyl) method ${ }^{15}$. This test was carried out by extracting $\beta$-carotene from the encapsulated powder. As much as $10 \mathrm{mg}$ of encapsulated powder were weighed and placed in a test tube. Into the test tube, $1 \mathrm{~mL}$ double-distilled water, $2 \mathrm{~mL}$ ethanol and $3 \mathrm{~mL}$-hexane was added. The solution mixture was heated for 2 minutes and subjected to the vortex. The top layer was taken and collected in an evaporation flask. The extraction step was repeated until the bottom layer vanished, indicating that all $\beta$-carotene has been extracted completely. The top layer was evaporated using a rotary evaporator and the obtained $\beta$-carotene was dissolved again in ethanol and diluted to produce a certain dilution concentration. Some portion of $\beta$-carotene solutions in evaporation samples were analysed using a visible spectrophotometer at a wavelength of $450 \mathrm{~nm}$ against an ethanol solution blank and another portion of $\beta$-carotene solution was used for antioxidant activity test. 
The antioxidant activity test was carried out as follows. A total of $0.5 \mathrm{~mL}$ of sample (a series of standard solutions of $\beta$-carotene, a series of standard solutions of vitamin $\mathrm{C}$, a series of FN extracts, and a series of FH extract solution) was taken and added with $3.5 \mathrm{~mL}$ of $75 \mu \mathrm{m} \mathrm{DPPH} \mathrm{radical} \mathrm{dissolved} \mathrm{in} 96 \%(\mathrm{v} / \mathrm{v})$ ethanol. The mixture was allowed to stand for 30 minutes at room temperature in a dark condition while stirring. The control solution was prepared in the same way as the sample solution, but $0.5 \mathrm{~mL}$ sample was replaced by $96 \%$ of ethanol (v/v). The absorbance of the DPPH radical was then measured by a UV-Vis spectrophotometer using $96 \%$ ethanol (v/v) as a blank solution at a wavelength of $517 \mathrm{~nm}$. The value of antioxidant activity (RSA: Radical Scavenging Activity) was calculated by eqn.-(2).

$$
\operatorname{RSA}(\%)=1-\frac{A_{\text {sample }}}{A_{\text {control }}} \times 100 \%
$$

Where:

$A_{\text {sample }}=$ Absorbance of sample

$A_{\text {control }}=$ Absorbance of control

Meanwhile, the inhibition concentration $\left(\mathrm{IC}_{50}\right) \beta$-carotene extract against DPPH radical was calculated by the standard curve method.

\section{Release Test in In-vitro Digestive Solution}

\section{RESULTS AND DISCUSSION}

In vitro release of $\beta$-carotene was carried out on AGF and AIF media. AGF and AIF contain digestive salts with $\mathrm{pH}$ close to physiological $\mathrm{pH}$ without the addition of enzymes. FN and $\mathrm{FH}$ show faster release in AGF than in AIF (Fig.-1). This can be associated with the very low pH of AGF solution $(\mathrm{pH}=1)$ so that it dissolves chitosan more rapidly. The dissolution of chitosan can create cavities that accelerate the diffusion of $\beta$-carotene into the release media. Chitosan is a polycation with a $\mathrm{pKa}$ in the range of 6.0-6.5. In an aqueous solution with a $\mathrm{pH}$ lower than its $\mathrm{pKa}$ value, chitosan undergoes dissolution and thus accelerates the drug diffusion. The crosslinking of TPP to chitosan decreases the $\mathrm{pKa}$ and therefore enhances the acid resistance of chitosan. For example, beads made of TPPcross-linked chitosan remain undissolved for 7 days when it is immersed in a solution with a $\mathrm{pH}$ of 3.0-5.0, but at a $\mathrm{pH}$ of 1.2 the beads completely dissolved after 1 hour of immersion. ${ }^{16}$ Although chitosan and starch are stable in AIF medium because it has $\mathrm{pH}$ of 6.8 , water may enter the capsule cavity that causes swelling. This swelling does not continue to damage the structure of starch (gelatinization) because the in-vitro digestive temperature is $37^{\circ} \mathrm{C}$. This condition causes $\beta$-carotene available in the matrix to become more difficult to get out. Moreover, chitosan does not dissolve at $\mathrm{pH} 6.8$, so it makes $\beta$-carotene much more difficult to release.

In AGF and AIF, FN shows a faster release than FH. This is probably due to the smaller size of $\mathrm{FH}^{7}$ so that the interaction of $\beta$-carotene with chitosan is stronger and the matrix is more tightly held so that it more difficult to diffuse $\beta$-carotene. Within 70 hours, the highest release is achieved by FN in the AGF medium. $\beta$-Carotene release in the stomach and intestines is a useful process to treat diseases of the stomach and intestines. In addition, the adsorption of $\beta$-carotene by the intestine is an essential phenomenon to increase vitamin A levels in the body.

\section{Release Test in Absolute Ethanol Media}

$\beta$-Carotene is often added in ethanol-based solutions, especially in the fields of medicine, cosmetics, and sanitizer equipment such as acne lotions and hand sanitizer. ${ }^{17} \beta$-Carotene added in alcoholic solutions will experience continuous degradation, therefore its activity is also continuously reducing. In this section, we investigate the release performance of $\beta$-carotene encapsulated in the matrix of starch-chitosan/TPP in ethanol media and the results are presented in Fig.-2. From this figure, it is seen that within 0-1 hours, a rapid release of $\beta$-carotene is observed followed by a slow $\beta$-carotene release from 1-4 hours. The rate of $\beta$-carotene release in absolute ethanol medium for FN matrix is almost the same as that for $\mathrm{FH}$, but there is an observable trend that the release rate of $\beta$-carotene for FH is slightly slower. This is probably due to a slightly stronger bond in $\mathrm{FH}$ than that in FN resulted from the smaller particle size found in $\mathrm{FH}^{7}$. The very small difference in bond strength between $\mathrm{FH}$ and $\mathrm{FN}$ gives rise to insignificant differences in their $\beta$ carotene release performance. 
RASĀYAN J. Chem.

Vol. 14 | No. 3 |1729-1735| July - September | 2021

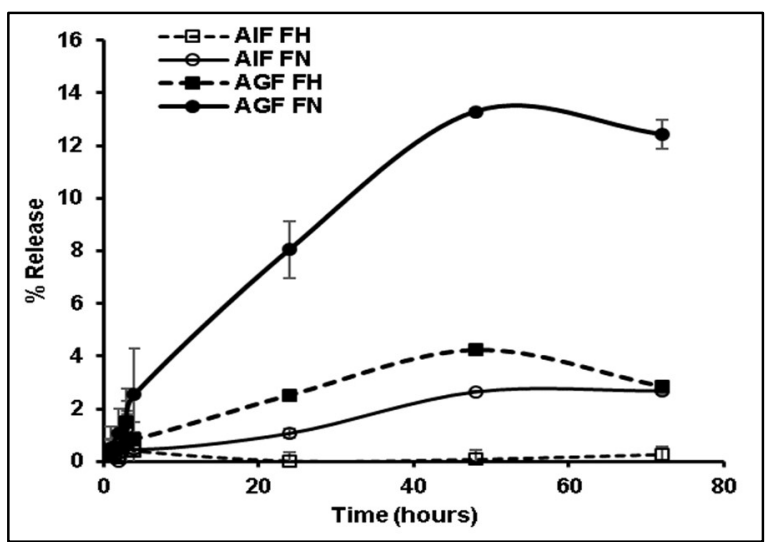

Fig.-1: $\beta$-Carotene release in artificial digestive media

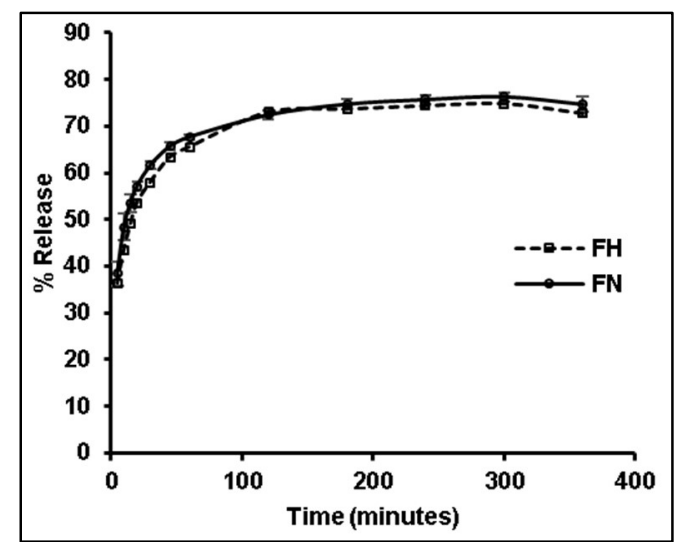

Fig.-2: $\beta$-Carotene release in ethanol

Kinetic Release of $\beta$-carotene in Absolute Ethanol Medium

To find out the kinetic release of $\beta$-carotene in absolute ethanol medium, the experimental data of the release were evaluated following the kinetic equations models listed in Table-1 and the related plots of the zeroorder, first-order, Higuchi, and Korsmeyer-Peppas (KP) kinetic models of drug release as given in Fig.-3. The linearity values $\left(\mathrm{R}^{2}\right)$ of the plots for zero-order, first-order, Higuchi and Korsmeyer-Peppas kinetic models of drug release are respectively $0.6036,0.6977,0.7697$, and 0.8962 for FN matrices and 0.6148 , $0.6996,0.7831$ and 0.9101 for FH.

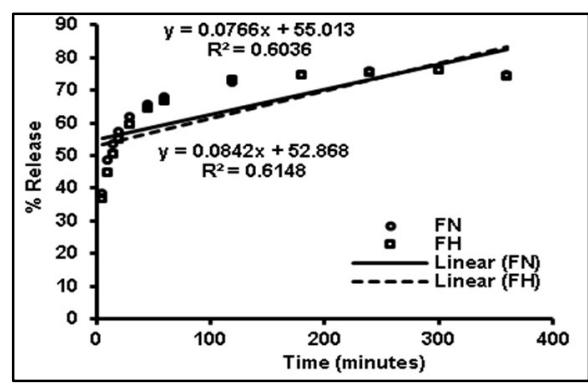

(a)

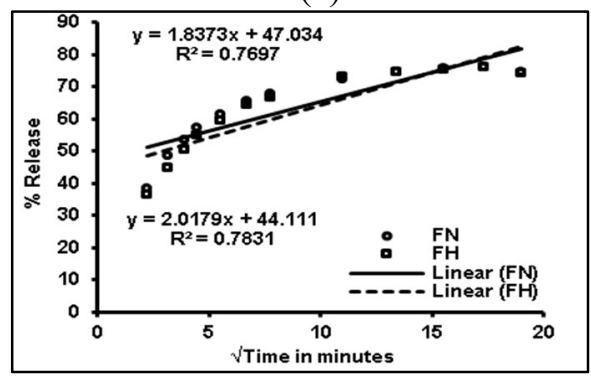

(c)

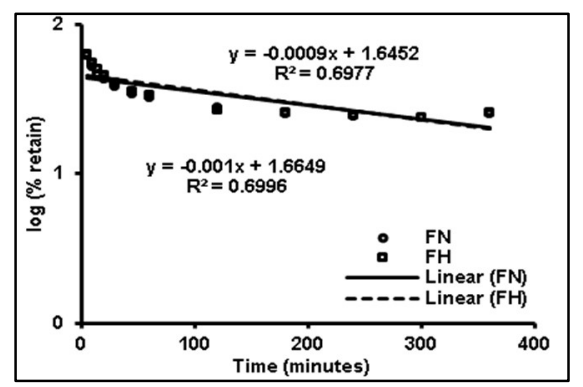

(b)

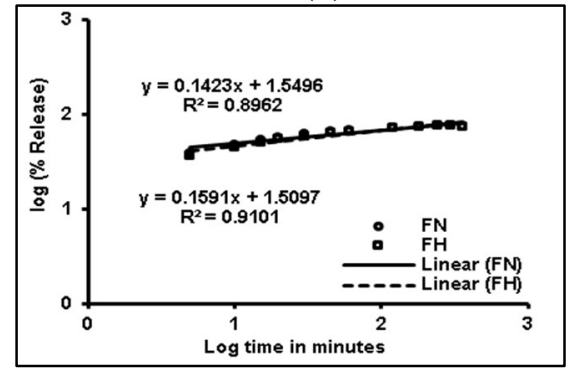

(d)

Fig.-3: The Kinetic Plot of $\beta$-carotene release in Ethanol Media for FN and FH Samples according to (a) Zero-order, (b) First-order, (c) Higuchi, and (d) Korsmeyer-Peppas Kinetic Models

Considering the highest $\mathrm{R}^{2}$ value of the plot as illustrated in Fig.-3, it is easily understood that the most suitable model for the kinetics of $\beta$-carotene release is the KP model. The parameter calculations of release kinetics of $\beta$-carotene from the starch-chitosan/TPP matrix according to the KP kinetics gives the exponent of release (n) values of 0.14 and 0.16 for $\mathrm{FN}$ and $\mathrm{FH}$, respectively. The value of $\mathrm{n}$ is obtained from the slope of plots of $\log$ time $(\mathrm{t})$ versus $\log$ (\%release) according to the kinetic equation of KP as listed in Table- 1. The value of $n$ in the range of less than 0.45 indicates that the $\beta$-carotene release occurs through fickian diffusion mechanism without causing any damage to the matrix. The following three stages of $\beta$-carotene release from $\beta$-carotene microcapsules may be proposed, i.e. (1) Ethanol diffuses in the matrix so that the 
matrix swells, (2) $\beta$-carotene in the matrix dissolves in ethanol, and then (3) $\beta$-carotene diffuses out of the matrix along with ethanol. The same mechanism also has been reported by another work suggesting that the kinetics of $\beta$-carotene release in aqueous media from a PEG (polyethylene glycol) polymer matrix modified with an amphiphilic copolymer follows the Korsmeyer-Peppas release kinetics with an exponent $\mathrm{n}$ value of less than $0.45 .^{18}$

\section{Antioxidant Activity}

To get information about the antioxidant activity of $\beta$-carotene after being encapsulated in the microcapsules, extraction of $\beta$-carotene from the encapsulated sample has been carried out using a mixture of hexane, ethanol, and water. The extracted $\beta$-carotene is dissolved again in ethanol solvent and its antioxidant activity is determined by the DPPH method. The antioxidant activity of vitamin $\mathrm{C}$ and free (non-encapsulated) $\beta$-carotene is also examined using the same procedure and the results are used as a positive control.

Figure- 4 shows that $\mathrm{IC}_{50}$ value of free $\beta$-carotene is much higher than that of encapsulated $\beta$-carotene extract or vitamin $C$. This means that the antioxidant activity of free $\beta$-carotene is lower than that of the encapsulated $\beta$-carotene extract or vitamin $C$. When compared with vitamin $E$ (tocopherol), the antioxidant value of vitamin $C>V$ itamin $E>\beta$-carotene. ${ }^{19}$ As the activity of encapsulated $\beta$-carotene is almost the same as vitamin $C$, these findings suggest that the encapsulation system of $\beta$-carotene can maintain its antioxidant activity or in other words, the encapsulated matrix is quite effective in protecting/preserving the activity of $\beta$-carotene. The value of the antioxidant activity of $\beta$-carotene which is in the order of free $<\mathrm{FH}<\mathrm{FN}$ is probably also contributed by the lipid content derived from starch or chitosan used as a matrix. The lipids may also be co-extracted into hexane solvent. As we know, lipids have $\mathrm{H}$ atoms that can be donated to $\mathrm{DPPH}$, hence it gives the higher result of antioxidant activity in the test. Acid hydrolysis usually reduces lipid content in $\operatorname{starch}^{20}$, therefore it is quite understandable that the antioxidant activity of the hydrolyzed starch as in FH sample is somewhat lower than that of FN sample.

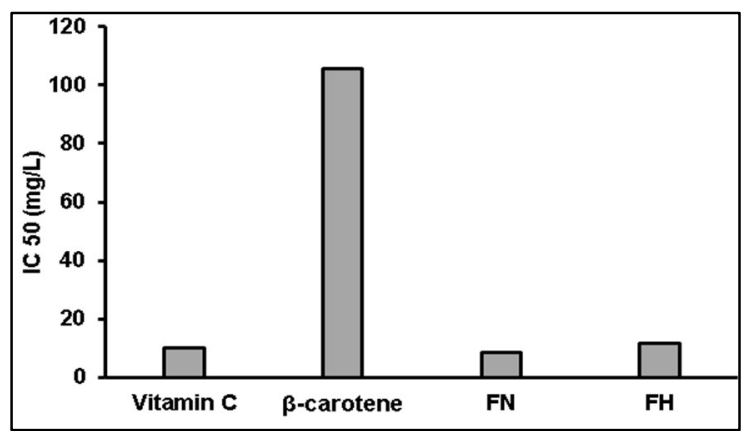

Fig.-4: Antioxidant Activity of Vitamin C, $\beta$-carotene, FN, and FH

\section{CONCLUSION}

The release of encapsulated $\beta$-carotene from the starch-chitosan/TPP matrix and its antioxidant activity test have been evaluated. Two types of starch have been used in this study, i.e. native starch and hydrolyzed starch. The release of $\beta$-carotene from AIF is slower than that from AGF. In each medium studied, the rate of $\beta$-carotene release was slower in FH samples compared to the corresponding FN samples. Kinetics of the $\beta$-carotene release from encapsulated samples in absolute ethanol media follows the Korsmeyer-Peppas release model with $\mathrm{n}$ values for FN and FH of 0.14 and 0.16 , respectively. These values indicate that the mechanism of $\beta$-carotene release is described by quasi-fickian diffusion. Furthermore, it is observed that the antioxidant activity of $\beta$-carotene shows no significant decrease after encapsulation, indicating the effectiveness of the encapsulation matrix in preserving $\beta$-carotene.

\section{ACKNOWLEDGEMENT}

The financial support from the Directorate of Research and Community Services, Ministry of Research and Technology/BRIN, Indonesia through doctoral dissertation research grant for the fiscal year of 2019-2020 to the first author (A.D.N.L.) is gratefully acknowledged. 
RASĀYAN J. Chem.

Vol. 14 | No. 3 |1729-1735| July - September | 2021

\section{REFERENCES}

1. N. M. Saptarini, G. Hadisoebroto, Rasayan Journal of Chemistry, 13(2), 789(2020), http://dx.doi.org/10.31788/RJC.2020.1325533

2. S. E. Cahyaningrum, N. Herdyastuti, W. Imroni, A. Sholikhah, Rasayan Journal of Chemistry, 13(1), 389 (2020), http://dx.doi.org/10.31788/RJC.2020.1315551

3. J. B. Wirjosentono, T. L. Marpaung, Rasayan Journal of Chemistry, 12(3), 1157(2019), http://dx.doi.org/10.31788/RJC.2019.1235378

4. J. Y. Kim, K. C. Huber, Carbohydrate Polymers, 136, 394(2016), https://doi.org/10.1016/j.carbpol.2015.08.069

5. Q. Wang, N. Zhang, X. Hu, J. Yang, Y. Du, European Journal of Pharmaceutics and Biopharmaceutics, 66, 398(2007), http://dx.doi.org/10.1016/j.ejpb.2006.11.011

6. S. B. Subramanian, A. P. Francis, T. Devasena, Carbohydrate Polymers, 114, 170(2014), http://dx.doi.org/10.1016/j.carbpol.2014.07.053

7. A. D. N. Lestari, D. Siswanta, R. Martien, M. Mudasir, Indonesan Journal of Chemistry, 20(4), 929(2020), http://dx.doi.org/10.22146/ijc.50449

8. X. Y. Lu, D. C. Wu, Z. J. Li, G. Q. Chen, Book Chapter of Progress in Molecular Biology and Translational Science. Polymer Nanoparticles. 104, Elsevier Inc., 299(2011), http://dx.doi.org/10.1016/B978-0-12-416020-0.00007-3299

9. S. E. Cahyaningrum, A. M. Sholikhah, Rasayan Journal of Chemistry, 14(2), 1273(2021), http://dx.doi.org/10.31788/RJC.2021.1426218

10. P. Nidhi, C. Anamika, S. Twinkle, S. Mehul, Hitesh, Indo American Journal of Pharmaceutical Sciences, 3(3), 227(2016).

11. A. D. N. Lestari, Mudasir, D. Siswanta, R. Martien, In Proceedings of The AIP Conference Proceedings of ISoC 2018, Indonesia, 2049, 020045 (2018), http://dx.doi.org/10.1063/1.5082450

12. O. S. Lawal, K. O. Adebowale, Carbohydrate Polymers, 60, 331(2005), http://dx.doi.org/10.1016/j.carbpol.2005.01.011

13. Y. Yuan, Y. Gao, J. Zhao, L. Mao, Food Research International. 41(1), 61(2008), http://dx.doi.org/10.1016/j.foodres.2007.09.006

14. J. K. Rutz, C. D. Borges, R. C. Zambiazi, G. Cleonice, M. Médelin, Food Chemistry, 202, 324(2016), http://dx.doi.org/10.1016/j.foodchem.2016.01.140

15. K. Mishra, H. Ojha, N. K. Chaudhury, Food Chemistry, 130, 1036(2012), http://dx.doi.org/10.1016/j.foodchem.2011.07.127

16. A. J. Worthen, K. S. Irving, Y. Lapitsky, Gels 5(1), 11(2019), http://dx.doi.org/10.3390/gels5010011

17. O.F. Science, Alcohol Hand Sanitizer With Improved Dermal Compatibility And Feel, US Patent, Pub. No .: US 2016/0271610 A1. 1, (2016).

18. B. B. Singh, N. A. Shakil, J. Kumar, S. Walia, A. Kar, Journal of Food Science and Technology, 52, 8068(2015), http://dx.doi.org/10.1007/s13197-015-1925-X

19. J. Chen, J. Shi, L. Macnaughton, Y. Kakuda, S.J. Xue, Y.Ma, M. Zhang, Y. Jiang, Journal of Food Biochemistry, 33, 232(2009), https://doi.org/10.1111/j.1745-4514.2009.00214.x

20. E. I. Yousif, M. G. E. Gadallah, A. M. Sorour, Annals of Agricultural Science, 57(1), 19(2012), http://dx.doi.org/10.1016/j.aoas.2012.03.008

[RJC-6217/2020] 